\title{
DISTRIBUIÇÃO DE NUTRIENTES E SINTOMAS VISUAIS DE DEFICIÊNCIA DE BORO EM RAÍZES DE COQUEIRO-ANÃO VERDE ${ }^{(1)}$
}

\author{
Leandro Glaydson da Rocha Pinho ${ }^{(2)}$, Pedro Henrique Monnerat ${ }^{(3)}$, André \\ Assis Pires ${ }^{(4)}$, Claudio Roberto Marciano ${ }^{(5)}$ \& Yaska Janaína Bastos Soares ${ }^{(6)}$
}

\section{RESUMO}

As raízes, geralmente, são os primeiros órgãos das plantas a apresentarem sintomas de deficiência de B. Plantas de grande porte são difíceis de serem manipuladas experimentalmente a fim de diagnosticar os efeitos das deficiências minerais em seus sistemas radiculares. Neste experimento, objetivou-se elucidar o efeito da deficiência de $B$ na formação de raízes de diferentes diâmetros e na acumulação de nutrientes, bem como caracterizar sintomas visuais da deficiência de $B$ em raízes de coqueiro-anão verde. Foram aplicados os seguintes tratamentos: solução nutritiva completa (+B) e solução nutritiva sem B (-B), distribuídos em delineamento inteiramente casualizado, com seis repetições. A unidade experimental constou de uma planta em um vaso plástico com $90 \mathrm{~L}$ de areia de praia purificada. Até o $60^{\circ}$ dia após o transplante (4/3/2006), todas as plantas receberam solução nutritiva completa. No 61ㅇ dia depois do transplante, aplicaramse os tratamentos citados. Decorridos 513 dias da indução da deficiência, coletaramse as raízes (1/6/2007); após o processo de lavagem, as raízes foram então separadas em três diâmetros: finas (<1 $\mathrm{mm})$, médias $(1 \mathrm{a} 5 \mathrm{~mm})$ e grossas ( $>5 \mathrm{~mm})$. Depois da separação, imergiram-se as raízes em água várias vezes para retirada da areia e, finalmente, elas foram lavadas em água desionizada. Após secagem em estufa, determinou-se a massa seca de cada tipo de raiz e, posteriormente, os teores de $\mathbf{N}$, $\mathrm{P}, \mathrm{K}, \mathrm{Ca}, \mathrm{Mg}, \mathrm{S}, \mathrm{B}, \mathrm{Cu}$, Fe, Mn e Zn. Os resultados indicaram que os maiores teores

\footnotetext{
(1) Parte da Tese de Doutorado do primeiro autor apresentada ao Centro de Ciências e Tecnologias Agropecuárias da Universidade Estadual do Norte Fluminense Darcy Ribeiro - UENF. Projeto financiado pela FAPERJ - Processo No E-26/152.352/2002. Recebido para publicação em dezembro de 2007 e aprovado em setembro de 2008.

(2) Doutorando em Produção Vegetal, Centro de Ciências e Tecnologias Agropecuárias da Universidade Estadual do Norte Fluminense Darcy Ribeiro - CCTA-LFIT-UENF. Av. Alberto Lamego 2000, CEP 28015602 Campos dos Goytacazes (RJ). Email: pinho@uenf.br

(3) Professor Titular, CCTA-LFIT-UENF. E-mail: monnerat@uenf.br

(4) Professor da Escola Agrotécnica Federal de Colatina. Rodovia BR 259, Km 70, CEP 29709-910 Colatina (ES). E-mail: assis@eafcol.br

(5) Professor Associado, CCTA-LSOL-UENF. E-mail: marciano@uenf.br

(6) MSc. em Produção Vegetal, CCTA-LMGV-UENF. E-mail: yaskasoares@yahoo.com.br
} 
de N, P, Ca, Mg, S, B, Cu, Fe, Mn e Zn foram encontrados nas raízes finas do coqueiro em ambos os tratamentos, porém os de $\mathrm{K}$ foram maiores nas raízes grossas. A deficiência de $\mathrm{B}$ aumentou os teores de $\mathrm{N}, \mathrm{P}$ e K em todas as raízes, os teores de $\mathrm{Mg}$, $\mathrm{S}$, Cu e Zn nas raízes finas, mas não afetou os teores de Ca, Fe e Mn. A deficiência de $B$ reduziu a produção de raízes totais e finas em 29,7 e 48,3 \%, respectivamente, e promoveu o engrossamento e escurecimento das raízes com ramificações curtas; as pontas das raízes necrosaram, causando superbrotamento radicular.

Termos de indexação: necrose, engrossamento, solução nutritiva, distribuição radicular, micronutriente.

\title{
SUMMARY: NUTRIENT DISTRIBUTION AND VISUAL SYMPTOMS OF BORON DEFICIENCY INROOTS OF GREEN DWARF COCONUT
}

\begin{abstract}
Roots are usually the first plant organs where boron deficiency symptoms appear. The experimental evaluation of the effects of mineral deficiencies on the root system of trees is rather difficult. This experiment aimed to evaluate the effect of boron deficiency on the formation of roots with different diameters and on nutrient accumulation and to characterize visual symptoms of $B$ deficiency in roots of green dwarf coconut trees. The following treatments were applied: complete nutrient solution $(+B)$ and nutrient solution without boron $(-B)$ in a randomized design, with six replicates. The experimental unit consisted of one plant in a plastic pot containing $90 \mathrm{~L}$ of purified beach sand. Until the $60^{\text {th }}$ day (3/04/2006), all plants were treated with a complete nutrient solution. On the $61^{\text {st }}$ day after transplanting the above treatments were applied. The roots were collected 513 days (6/01/2007) after the induction of deficiency. After washing, the roots were separated in three diameters: fine $(<1 \mathrm{~mm})$, medium $(1$ to $5 \mathrm{~mm})$ and thick $(>5 \mathrm{~mm})$. After the separation, the roots were immersed in water several times to remove the sand and finally washed in deionized water. After oven-drying, the dry matter of each root type was determined and thereafter the concentrations of $\mathrm{N}, \mathrm{P}, \mathrm{K}, \mathrm{Ca}, \mathrm{Mg}, \mathrm{S}, \mathrm{B}, \mathrm{Cu}, \mathrm{Fe}, \mathrm{Mn}$, and $\mathrm{Zn}$ were determined. Results indicated that the highest $\mathrm{N}, \mathrm{P}, \mathrm{Ca}, \mathrm{Mg}, \mathrm{S}, \mathrm{B}, \mathrm{Cu}, \mathrm{Fe}, \mathrm{Mn}$, and $Z n$ concentrations were found in the fine roots of the coconut tree in both treatments, but those of $K$ were higher in the thick roots. The boron deficiency increased the $N, P$ and $K$ concentrations in all roots, the $\mathrm{Mg}, \mathrm{S}, \mathrm{Cu}$ and $\mathrm{Zn}$ concentrations in the fine roots, but $\mathrm{Ca}, \mathrm{Fe}$ and $M n$ were not affected. The boron deficiency reduced the production of total and fine roots by 29.7 and $48.3 \%$, respectively; it induced root thickening and darkening and short ramifications; the root tips died off, causing root overgrowth.
\end{abstract}

Index terms: necrosis, root thickning, nutrient solution, root distribution, boric acid.

\section{INTRODUÇÃO}

Em uma série de culturas, a deficiência de B, entre outros efeitos, resultou em menor crescimento radicular (Lima Filho \& Malavolta, 1997; Lovatt et al., 1981; Viégas et al., 2004). As raízes são os órgãos responsáveis pela fixação das plantas ao solo e pela absorção de água e nutrientes (Fitter, 1991). A absorção de água e nutrientes parece ser realizada, preferencialmente, por raízes finas (Russel, 1981).

Da mesma forma, no coqueiro, a absorção de nutrientes por raízes de primeira ordem é baixa, ficando restrita à pequena porção na ponta da raiz, localizada atrás da coifa (Frémond et al., 1975). De acordo com Passos (1998), as raízes de terceira ordem são as maiores responsáveis pela absorção de água e nutrientes, uma vez que o coqueiro não possui pêlos radiculares. Normalmente, das raízes de primeira ordem surgem raízes de segunda e, destas, as de terceira ordem (Passos, 1998). Possivelmente, a maior parte da absorção de nutrientes pelas raízes de coqueiro ocorre nos primeiros centímetros de solo, uma vez que as camadas superficiais deste apresentam a maior densidade de radicelas (Frémond et al., 1975; Cintra et al., 1996). Outros autores também encontraram maior percentual de radicelas na camada superficial de solo (Fabião et al., 1987; Witschoreck et al., 2003; Brasil, 2001).

Os primeiros sintomas de deficiência de $B$ são, de maneira geral, observados nas raízes (Lima Filho \& Malavolta, 1997; Lovatt, 1981). Em coqueiro deficiente em B, a parte aérea também fica comprometida, as folhas novas ficam menos expandidas, apresentam crestamento, necroses e pontos com cortiça, chegando 
a paralisar o crescimento da planta (Sobral, 1998; Macêdo et al., 1999; Santos et al., 2003; Broschat, 2005). Nesse caso, se na deficiência de B a planta de coqueiro apresentar perda da capacidade de formação de raízes, a planta fica exposta a um ambiente que poderá comprometer a absorção não só de $\mathrm{B}$, mas de vários outros nutrientes, tanto os que se movem por fluxo de massa no solo, como por difusão e interceptação radicular. Entretanto, não se conhece o efeito da deficiência de B no desenvolvimento e crescimento radicular do coqueiro.

A deficiência de $\mathrm{B}$ foi diagnosticada no Estado do Rio de Janeiro em plantios de coqueiro-anão verde (Mirisola Filho, 1997; Santos et al., 2003). A correção da deficiência foi possível com a aplicação de $15 \mathrm{~g}$ de bórax por planta na axila das folhas 2, 3 e 4 (Santos et al., 2003); as plantas rapidamente desenvolveram folhas normais, sem nenhum sintoma visual de deficiência de B.

A aplicação de B em plantas de coqueiro pode ser feita tanto na axila foliar (Sobral, 1998; Santos et al., 2003; Pinho, 2004) como no solo (Pinho, 2004), e em ambas as formas de aplicação ocorreu absorção do nutriente pela planta (Pinho, 2004). O incremento na absorção de B pelo coqueiro, com teor inicial de B de aproximadamente $8 \mathrm{mg} \mathrm{kg}^{-1}$ na folha 14 , foi acompanhado de elevação de $75 \%$ no número de frutos por cacho quando se aplicaram $80 \mathrm{~g} \mathrm{de} \mathrm{H}_{3} \mathrm{BO}_{3}$ por planta no solo e $30 \%$ quando foram aplicados $40 \mathrm{~g}$ de $\mathrm{H}_{3} \mathrm{BO}_{3}$ por planta na axila da folha 10 . Como as plantas elevaram a produtividade em resposta à aplicação de B, comprovou-se deficiência desse elemento, mesmo as folhas não apresentando sintomas visuais de deficiência.

Nos últimos 17 anos, grandes avanços foram alcançados no entendimento dos papéis do B no metabolismo vegetal, porém sua função primária ainda não está clara. Das funções atualmente atribuídas ao B, duas são aceitas pela comunidade científica: uma é como constituinte da parede celular - nela, o B, possivelmente, atuaria estabilizando-a (Matoh et al., 1993; Hu \& Brown, 1994; Ishii \& Matsunaga, 1996; Kobayaski et al., 1996; Fleischer et al., 1998; Pfeffer et al., 2001); a outra função seria a manutenção da integridade da membrana plasmática (Cakmak et al., 1995).

Neste experimento, objetivou-se esclarecer o efeito do $\mathrm{B}$ na formação de raízes de diferentes diâmetros e na sua acumulação de nutrientes, bem como caracterizar sintomas visuais da deficiência de B em raízes de coqueiro em fase de crescimento vegetativo.

\section{MATERIAL E MÉTODOS}

Realizou-se o experimento com plantas de coqueiroanão verde (Cocos nucifera L.), entre 5 de janeiro de
2006 e 1o de junho de 2007 , em casa de vegetação localizada no campus da Universidade Estadual do Norte Fluminense Darcy Ribeiro-RJ. As coordenadas geográficas da casa de vegetação são: $21^{\circ} 45^{\prime} 39,99$ ” S e $41^{\circ} 17^{\prime} 20,93$ ” W. Os tratamentos consistiram de solução nutritiva completa $(+\mathrm{B})$ e solução nutritiva sem adição de $\mathrm{B}(-\mathrm{B})$, em delineamento experimental inteiramente casualizado, com seis repetições. A unidade experimental constou de uma planta em um vaso plástico com $90 \mathrm{~L}$ de areia de praia purificada. $\mathrm{O}$ vaso consistiu de um tambor cortado ao meio, cuja drenagem foi feita por 57 perfurações de $5 \mathrm{~mm}$ de diâmetro. A purificação da areia se fez por meio de sua embebição em ácido clorídrico diluído em água na proporção de 1:4 durante cerca de quatro horas e posterior lavagem com água comum até que o $\mathrm{pH}$ se aproximasse de 5,0, quando, então, fez-se a última lavagem com água desionizada.

Em 5 de janeiro de 2006, selecionaram-se as mudas de mesma origem, variedade e com 11 meses de idade em um viveiro situado na fazenda Taí Agropecuária, em Campos dos Goytacazes, retirando-se plantas com sete folhas e saudáveis. O sistema radicular das plantas foi umedecido e protegido com sacolas plásticas. As plantas foram imediatamente transportadas para a casa de vegetação, onde se efetuou uma toalete, eliminando-se a amêndoa e podando as raízes a $25 \mathrm{~cm}$ da base, sendo cada planta transplantada para o vaso com areia. Após o transplante, as mudas foram irrigadas com água desionizada até a saturação da areia. As irrigações passaram, então, a ser feitas automaticamente, por meio de uma bomba controlada por um temporizador, oito vezes ao dia, aplicando-se $3 \mathrm{~L}$ de água desionizada por irrigação. O turno de rega foi de duas horas, iniciando-se diariamente às $6 \mathrm{~h}$ e finalizando às $20 \mathrm{~h}$, aplicando-se água durante $15 \mathrm{~min}$, por meio de dois gotejadores.

Durante a condução do experimento, registraramse diariamente as temperaturas máximas e mínimas com um termômetro digital, com sensor de temperatura colocado junto à folha de uma das plantas (Figura 1).

Para acompanhar a tensão de água no vaso, instalaram-se em quatro vasos, dois de cada tratamento, dois tensiômetros: um de $10-15 \mathrm{~cm}$ de profundidade e outro de $20-25 \mathrm{~cm}$. As leituras da altura da coluna de $\mathrm{Hg}$ eram realizadas diariamente por meio de régua graduada, com precisão de $1 \mathrm{~mm}$. Calculou-se o potencial mátrico por meio da fórmula: $\Psi_{\mathrm{M}}=-12,6 \mathrm{H}+Z+h_{c}$, em que $\Psi_{\mathrm{M}}$ representa o potencial mátrico; $\mathrm{H}$, a leitura da altura da coluna de $\mathrm{Hg}$ no tensiômetro; $h_{c}$, a distância do nível de $\mathrm{Hg}$ na cuba à superfície da areia no momento da leitura; $\mathrm{Z}$, a profundidade de instalação da cápsula (Libardi, 1995). Procurou-se manter a areia constantemente úmida, não permitindo grandes oscilações na tensão entre duas irrigações subseqüentes. Das tensões calculadas, os valores das tensões máxima, mínima e 
média, da tensão mais repetida e desvio-padrão encontram-se no quadro 1.

Foram aplicados uma vez ao dia, em cada planta, 2,5 L de solução nutritiva com $\mathrm{pH}$ ajustado a 5,5 \pm 0,2. Durante os primeiros 10 dias, todas as plantas receberam a solução completa a $1 / 4$ de força iônica; após esse período, as plantas receberam durante cinco dias a solução a $\frac{1}{2}$ de força iônica. Do $16^{\circ}$ dia até o $60^{\circ}$ dia após o plantio aplicou-se, em todas as plantas, a solução nutritiva completa a uma força iônica (Quadro 2). No 61ํ dia, aplicaram-se os tratamentos.

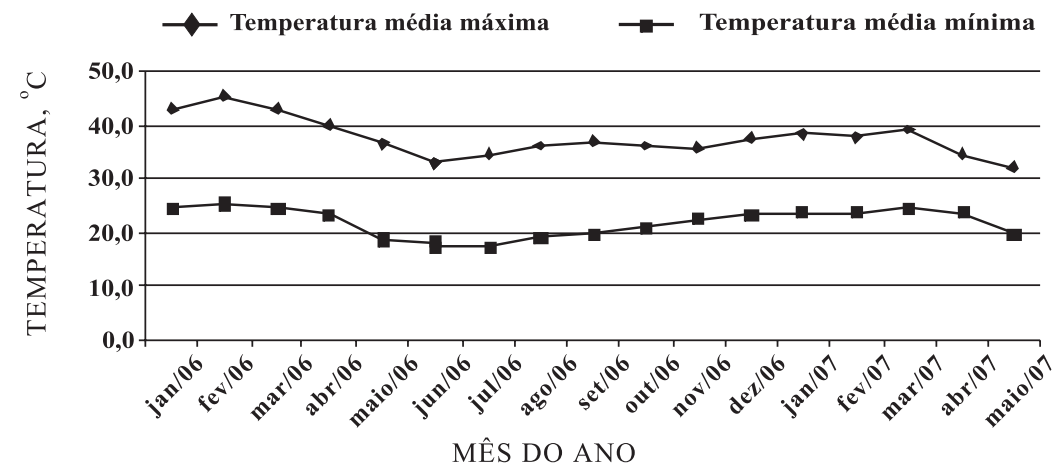

Figura 1. Temperaturas máximas e mínimas (médias mensais) obtidas no interior da casa de vegetação. Campos dos Goytacazes, 2007.

Quadro 1. Valores máximo, mínimo, médio, mais freqüente e desvio-padrão, da tensão da água na areia durante o experimento. Campos dos Goytacazes, 2007

\begin{tabular}{ccccccc}
\hline \multirow{2}{*}{ Tratamento } & Profundidade & TM & TMIM & Média & TR & DP \\
\hline \multirow{2}{*}{ - B } & $10-15$ & & & & & \\
\cline { 5 - 7 } & $20-25$ & $-0,54$ & $-0,30$ & $-0,39$ & $-0,41$ & 0,033 \\
+B & $10-15$ & $-0,49$ & $-0,21$ & $-0,36$ & $-0,34$ & 0,043 \\
& $20-25$ & $-0,57$ & $-0,28$ & $-0,41$ & $-0,38$ & 0,048 \\
& $-0,55$ & $-0,21$ & $-0,39$ & $-0,39$ & 0,042 \\
\hline
\end{tabular}

Prof.: profundidade; TM: tensão máxima; TMIM: tensão mínima; TF: tensão mais freqüente; DP: desvio-padrão; mc.a = metros de coluna de água.

Quadro 2. Composição da solução nutritiva completa utilizada no experimento

\begin{tabular}{lc}
\hline Macronutrientes & Concentração \\
\hline & $\mathrm{mmol} \mathrm{L}^{-1}$ \\
$\mathrm{Ca}\left(\mathrm{NO}_{3}\right)_{2} 2 \mathrm{H}_{2} \mathrm{O}$ & 3 \\
$\mathrm{NH}_{4} \mathrm{NO}_{3}$ & 1 \\
$\mathrm{KH}_{2} \mathrm{PO}_{4}$ & 0,25 \\
$\mathrm{KNO}_{3}$ & 4 \\
$\mathrm{MgSO}_{4} 7 \mathrm{H}_{2} \mathrm{O}$ & 1 \\
Micronutrientes & \\
$\mathrm{Fe}-\mathrm{EDTA}^{(1)}$ & $80^{(1)}$ \\
$\mathrm{MnSO}_{4}$ & 5 \\
$\mathrm{ZnSO}_{4} 7 \mathrm{H}_{2} \mathrm{O}$ & 2 \\
$\mathrm{CuSO}_{4} 5 \mathrm{H}_{2} \mathrm{O}$ & 0,5 \\
$\left(\mathrm{NH}_{4}\right)_{6} \mathrm{MoO}_{7} \mathrm{O}_{24}$ & 0,086 \\
$\mathrm{KCl}$ & 50 \\
$\mathrm{H}_{3} \mathrm{BO}_{3}$ & $50^{(2)}$
\end{tabular}

(1) $40 \mu \mathrm{mol} \mathrm{L}{ }^{-1}$ até $23 / 08 / 06$ e $80 \mu \mathrm{mol} \mathrm{L}{ }^{-1}$ após. ${ }^{(2)} 25 \mu \mathrm{mol} \mathrm{L}{ }^{-1}$ até 29/06/06 e $50 \mu \mathrm{mol} \mathrm{L}{ }^{-1}$ após.
Depois de colhida a parte aérea do coqueiro (29 de maio de 2007), procedeu-se à retirada do sistema radicular (1ำ de junho de 2007). Para retirada do sistema radicular intacto, foi necessário fazer um corte na parede lateral do vaso, sendo a maior parte da areia retirada por meio de jatos de água. A total remoção da areia só foi possível após a remoção das raízes da sua inserção ao estipe. As raízes foram então separadas em três diâmetros: finas $(<1 \mathrm{~mm})$, médias (1 a $5 \mathrm{~mm}$ ) e grossas (> $5 \mathrm{~mm})$.

Depois da separação, imergiram-se as raízes em água desionizada e, após a eliminação do excesso de água, mediu-se a massa de cada tipo de raiz úmida. Posteriormente, determinou-se a massa de quatro subamostras úmidas pertencentes a cada diâmetro radicular; depois, estas amostras foram acondicionadas em sacos de papel tipo Kraft, com posterior secagem por cinco dias consecutivos a $75^{\circ} \mathrm{C}$ em estufa de circulação forçada de ar. Os dados das amostras permitiram calcular a matéria seca de raízes finas, médias e grossas de cada planta. 
Após a obtenção da massa dos tecidos secos, moeram-se as raízes em moinho tipo Wiley, com peneira de 30 mesh. O material foi acondicionado em tubos hermeticamente vedados. Posteriormente, determinaram-se os teores de $\mathrm{N}, \mathrm{P}, \mathrm{K}, \mathrm{Ca}, \mathrm{Mg}, \mathrm{S}, \mathrm{B}$, $\mathrm{Cu}, \mathrm{Fe}, \mathrm{Zn}$ e Mn. As análises foram realizadas de acordo com métodos descritos por Malavolta et al. (1997), com o N, dosado pelo método de Nessler (Jackson, 1965); todos os métodos foram adaptados por Monnerat (não publicado).

Os dados foram submetidos à análise de variância e as médias, comparadas pelo teste de Tukey a $5 \%$.

\section{RESULTADOS}

\section{Matéria seca das raízes}

A deficiência de B reduziu em 29,7 \% a matéria seca total das raízes (Quadro 3). A maior parte da redução ocorreu devido à menor produção de raízes finas nas plantas sob deficiência de B (Quadro 3), cuja matéria seca foi $48,3 \%$ menor do que a do tratamento completo (+B).

Nas plantas deficientes em $B$ houve menor produção de matéria seca de raízes médias e finas, em comparação com a matéria seca de raízes grossas formadas nessas mesmas plantas. As plantas normais (+B) produziram mais matéria seca de raízes finas e grossas, quando comparadas com a produção de raízes médias, nessas plantas (Quadro 3). Nas plantas deficientes, do total de raízes produzidas $(2.993,3 \mathrm{~g})$, as grossas, médias e finas foram 52,0, 19,6 e 28,4\%, respectivamente.

\section{Teores de nutrientes nas raízes}

A deficiência de $\mathrm{B}$ aumentou os teores de $\mathrm{N}$ e $\mathrm{P}$ nas raízes do coqueiro. As raízes finas de ambos os tratamentos apresentaram os maiores teores desses nutrientes, e as raízes médias não diferiram das grossas (Quadro 4). O teor de K nas raízes foi também aumentado pela deficiência de B; entretanto, foram as raízes grossas as que apresentaram os maiores teores, e as médias e finas não diferiram entre si.

Os teores de $\mathrm{Ca}, \mathrm{Fe}$ e $\mathrm{Mn}$ não foram alterados significativamente pela deficiência de $\mathrm{B}$, sendo, entretanto, maiores nas raízes finas. As raízes grossas e médias não diferiram entre si (Quadro 4).

A deficiência de $\mathrm{B}$ aumentou o teor de $\mathrm{Mg}$ apenas na matéria seca das raízes finas. Tanto nas plantas deficientes de $\mathrm{B}$ como nas normais, o teor de $\mathrm{Mg}$ decresceu das raízes finas para as grossas (Quadro 4). Os teores de $\mathrm{S}$, $\mathrm{Cu}$ e $\mathrm{Zn}$ foram maiores nas plantas deficientes de B apenas nas raízes finas. Em ambos os tratamentos, as raízes médias e grossas não diferiram entre si, mas apresentaram teores desses nutrientes menores do que os das raízes finas (Quadro 4).

Em qualquer diâmetro avaliado, como era de se esperar, o menor teor de $\mathrm{B}$ foi obtido nas raízes das plantas deficientes (Quadro 4). Nas plantas deficientes, o teor de $\mathrm{B}$ foi maior nas raízes finas. Os teores de B, nas raízes das plantas normais, foram menores nas raízes médias, quando comparados com os teores obtidos nas raízes grossas e finas (Quadro 4). Nas plantas deficientes, a tendência foi a mesma.

\section{Sintomas visuais}

Comparando as raízes das plantas deficientes com as normais, percebeu-se de forma nítida um menor número de raízes finas nas plantas deficientes de $\mathrm{B}$ (Figura 2a,b,c). Nas plantas deficientes, as pontas de algumas raízes encontravam-se com superbrotação e necrosadas (Figura 2d,e). Comparando as raízes médias e finas das plantas normais (Figura 2f) com as raízes desses diâmetros das plantas deficientes (Figura 2g), percebeu-se que muitas das raízes deficientes eram mais curtas, grossas e com escurecimento. Nas plantas deficientes de B, a menor produção de matéria seca das raízes finas (Quadro 3) comprovou a observação visual de menor número destas raízes.

Quadro 3. Matéria seca e percentual de raízes de diferentes diâmetros de plantas normais de coqueiro-anão verde (+B) e deficientes de B (-B)

\begin{tabular}{|c|c|c|c|c|c|c|c|}
\hline \multirow{2}{*}{ Tratamento } & \multicolumn{4}{|c|}{ Matéria seca da raiz } & \multicolumn{3}{|c|}{ Percentual } \\
\hline & Fina & Média & Grossa & Total & Fina & Média & Grossa \\
\hline & \multicolumn{4}{|c|}{$\mathrm{g} /$ planta } & \multicolumn{3}{|c|}{ \% } \\
\hline$+\mathrm{B}$ & $1.681,1 \mathrm{Aa}$ & $740,6 \mathrm{Ba}$ & $1.836,8 \mathrm{Aa}$ & $4.258,5 \mathrm{a}$ & $39,6 \mathrm{Aa}$ & $17,3 \mathrm{Ba}$ & $43,1 \mathrm{Ab}$ \\
\hline$-\mathrm{B}$ & $869,5 \mathrm{Bb}$ & $573,9 \mathrm{Ba}$ & $1.549,9 \mathrm{Aa}$ & $2.993,3 b$ & $28,4 \mathrm{Ab}$ & $19,6 \mathrm{Ba}$ & $52,0 \mathrm{Aa}$ \\
\hline CV (\%) & \multicolumn{4}{|c|}{21,7} & \multicolumn{3}{|c|}{14,6} \\
\hline
\end{tabular}

Médias seguidas de mesma letra, maiúscula na linha e minúscula na coluna, não diferem estatisticamente entre si pelo teste de Tukey a $5 \%$. 


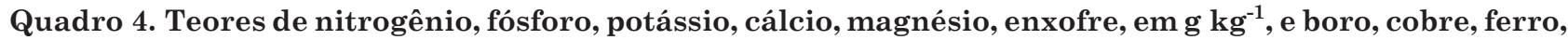
manganês e zinco, em $\mathrm{mg} \mathrm{kg}^{-1}$, nas raízes de diferentes diâmetros de plantas de coqueiro-anão verde normais (+B) e deficientes em boro (-B)

\begin{tabular}{|c|c|c|c|c|c|c|}
\hline \multirow{2}{*}{ Nutriente } & \multirow{2}{*}{ Tratamento } & \multicolumn{3}{|c|}{ Diâmetro radicular } & \multirow{2}{*}{\multicolumn{2}{|c|}{ Média }} \\
\hline & & Fina & Média & Grossa & & \\
\hline $\mathrm{N}$ & $\begin{array}{c}+\mathrm{B} \\
-\mathrm{B} \\
\text { Média }\end{array}$ & $\begin{array}{l}7,12 \\
8,09 \\
7,60 \mathrm{~A}\end{array}$ & $\begin{array}{l}4,60 \\
5,76 \\
5,18 \text { B }\end{array}$ & $\begin{array}{l}4,48 \\
6,01 \\
5,24 \text { B }\end{array}$ & $\begin{array}{r}5,40 \\
6,62 \\
\mathrm{CV}(\%)\end{array}$ & $\begin{array}{l}\mathrm{b} \\
\mathrm{a} \\
15,2\end{array}$ \\
\hline $\mathrm{P}$ & $\begin{array}{c}+\mathrm{B} \\
-\mathrm{B} \\
\text { Média }\end{array}$ & $\begin{array}{l}0,65 \\
0,76 \\
0,71 \mathrm{~A}\end{array}$ & $\begin{array}{l}0,50 \\
0,53 \\
0,52 \mathrm{~B}\end{array}$ & $\begin{array}{l}0,50 \\
0,53 \\
0,51 \mathrm{~B}\end{array}$ & $\begin{array}{r}0,55 \\
0,61 \\
\mathrm{CV}(\%)\end{array}$ & $\begin{array}{l}\mathrm{b} \\
\mathrm{a} \\
12,9\end{array}$ \\
\hline $\mathrm{K}$ & $\begin{array}{c}+\mathrm{B} \\
-\mathrm{B} \\
\text { Média }\end{array}$ & $\begin{array}{l}5,8 \\
7,8 \\
6,8 \mathrm{~B}\end{array}$ & $\begin{array}{l}7,4 \\
8,6 \\
8,0 \mathrm{~B}\end{array}$ & $\begin{array}{l}10,1 \\
11,6 \\
10,8 \mathrm{~A}\end{array}$ & $\begin{array}{r}7,8 \mathrm{~b} \\
9,3 \mathrm{a} \\
\mathrm{CV}(\%)\end{array}$ & 17,8 \\
\hline $\mathrm{Ca}$ & $\begin{array}{c}+\mathrm{B} \\
-\mathrm{B} \\
\text { Média }\end{array}$ & $\begin{array}{l}2,56 \\
3,17 \\
2,86 \mathrm{~A}\end{array}$ & $\begin{array}{l}1,10 \\
1,33 \\
1,21 \mathrm{~B}\end{array}$ & $\begin{array}{l}0,74 \\
0,87 \\
0,80 \mathrm{~B}\end{array}$ & $\begin{array}{r}1,46 \\
1,79 \\
\mathrm{CV}(\%)\end{array}$ & $\begin{array}{l}a \\
a \\
38,5\end{array}$ \\
\hline $\mathrm{Mg}$ & $\begin{array}{c}+\mathrm{B} \\
-\mathrm{B} \\
\text { Média }\end{array}$ & $\begin{array}{l}1,15 \mathrm{Ab} \\
1,40 \mathrm{Aa} \\
1,28\end{array}$ & $\begin{array}{l}1,04 \mathrm{Ba} \\
1,09 \mathrm{Ba} \\
1,06\end{array}$ & $\begin{array}{l}0,80 \mathrm{Ca} \\
0,81 \mathrm{Ca} \\
0,81\end{array}$ & $\begin{array}{r}1,00 \\
1,10 \\
\text { CV (\%) }\end{array}$ & 7,6 \\
\hline $\mathrm{S}$ & $\begin{array}{c}+\mathrm{B} \\
-\mathrm{B} \\
\text { Média }\end{array}$ & $\begin{array}{l}1,65 \mathrm{Ab} \\
2,03 \mathrm{Aa} \\
1,84\end{array}$ & $\begin{array}{l}0,79 \mathrm{Ba} \\
0,91 \mathrm{Ba} \\
0,85\end{array}$ & $\begin{array}{l}0,75 \mathrm{Ba} \\
0,80 \mathrm{Ba} \\
0,77\end{array}$ & $\begin{array}{r}1,06 \\
1,25 \\
\text { CV }(\%)\end{array}$ & 11,3 \\
\hline B & $\begin{array}{c}+\mathrm{B} \\
-\mathrm{B} \\
\text { Média }\end{array}$ & $\begin{array}{l}5,59 \mathrm{Aa} \\
4,27 \mathrm{Ab} \\
4,93\end{array}$ & $\begin{array}{l}3,93 \mathrm{Ba} \\
2,88 \mathrm{Bb} \\
3,40\end{array}$ & $\begin{array}{l}4,79 \mathrm{Aa} \\
3,37 \mathrm{Bb} \\
4,08\end{array}$ & $\begin{array}{r}4,77 \\
3,50 \\
\mathrm{CV}(\%)\end{array}$ & 13,8 \\
\hline $\mathrm{Cu}$ & $\begin{array}{c}+\mathrm{B} \\
-\mathrm{B} \\
\text { Média }\end{array}$ & $\begin{array}{l}41,9 \mathrm{Ab} \\
74,7 \mathrm{Aa} \\
58,3\end{array}$ & $\begin{array}{l}3,1 \mathrm{Ba} \\
4,8 \mathrm{Ba} \\
4,0\end{array}$ & $\begin{array}{l}1,9 \mathrm{Ba} \\
2,2 \mathrm{Ba} \\
2,0\end{array}$ & $\begin{array}{c}15,6 \\
27,2 \\
\text { CV (\%) }\end{array}$ & 36,8 \\
\hline $\mathrm{Fe}$ & $\begin{array}{c}+\mathrm{B} \\
-\mathrm{B} \\
\text { Média }\end{array}$ & $\begin{array}{l}325 \\
280 \\
303 \mathrm{~A}\end{array}$ & $\begin{array}{c}105 \\
83 \\
94 \mathrm{~B}\end{array}$ & $\begin{array}{l}64 \\
63 \\
64 \mathrm{~B}\end{array}$ & $\begin{array}{r}165 \mathrm{a} \\
142 \mathrm{a} \\
\mathrm{CV}(\%)\end{array}$ & 38,8 \\
\hline $\mathrm{Mn}$ & $\begin{array}{c}+\mathrm{B} \\
-\mathrm{B} \\
\text { Média }\end{array}$ & $\begin{array}{l}12,9 \\
19,7 \\
16,3 \mathrm{~A}\end{array}$ & $\begin{array}{l}4,5 \\
5,4 \\
5,0 \mathrm{~B}\end{array}$ & $\begin{array}{l}3,5 \\
3,5 \\
3,5 \text { B }\end{array}$ & $\begin{array}{r}7,0 \mathrm{a} \\
9,5 \mathrm{a} \\
\mathrm{CV}(\%)\end{array}$ & 58,5 \\
\hline $\mathrm{Zn}$ & $\begin{array}{c}+\mathrm{B} \\
-\mathrm{B} \\
\text { Média }\end{array}$ & $\begin{array}{l}25,0 \mathrm{Ab} \\
52,2 \mathrm{Aa} \\
38,6\end{array}$ & $\begin{array}{c}9,4 \mathrm{Ba} \\
10,2 \mathrm{Ba} \\
9,8\end{array}$ & $\begin{array}{l}5,6 \mathrm{Ba} \\
5,8 \mathrm{Ba} \\
5,7\end{array}$ & $\begin{array}{c}13,3 \\
22,7 \\
\text { CV (\%) }\end{array}$ & 28,0 \\
\hline
\end{tabular}

Para cada nutriente, médias seguidas de mesma letra, maiúscula na linha e minúscula na coluna, não diferem estatisticamente entre si pelo teste de Tukey a $5 \%$.

\section{DISCUSSÃO}

\section{Matéria seca das raízes}

A maior parte das raízes, nas plantas deficientes de B, era grossa (Quadro 3), correspondendo a $52 \%$ do total de raízes. Nos dois tratamentos, encontrouse menor produção percentual de raízes médias (Quadro 3); possivelmente, esta seja uma característica da arquitetura do sistema radicular do coqueiro. Freitas (2006) induziu deficiência de B em plantas de Passiflora edulis (maracujá-doce), mas não encontrou redução significativa na matéria seca da raiz. Esse autor adicionou $B$ nas plantas sob indução de deficiência. As adições durante o período de condução do experimento podem não ter permitido redução na matéria seca de raízes. As adições foram necessárias, uma vez que se objetivou a obtenção de sintomas visuais de deficiência de B nos frutos (Freitas, 2006). Viégas et al. (2004) encontraram em plantas de Myrciaria dubia (camucazeiro) deficientes de $\mathrm{B}$ redução na produção de matéria seca de raízes.

O B é um nutriente essencial para a formação de tecidos meristemáticos radiculares e caulinares $(\mathrm{Hu}$ et al.,1997; Belvins \& Lukaszewski, 1998), ou seja, na falta de B o crescimento e desenvolvimento radicular e caulinar paralisam. O B possui função importante no transporte de açúcares e no metabolismo do carboidrato (Dechen \& Nachtigall, 2006); associado a essas funções, a menor área foliar em plantas deficientes de B promove redução na produção de 

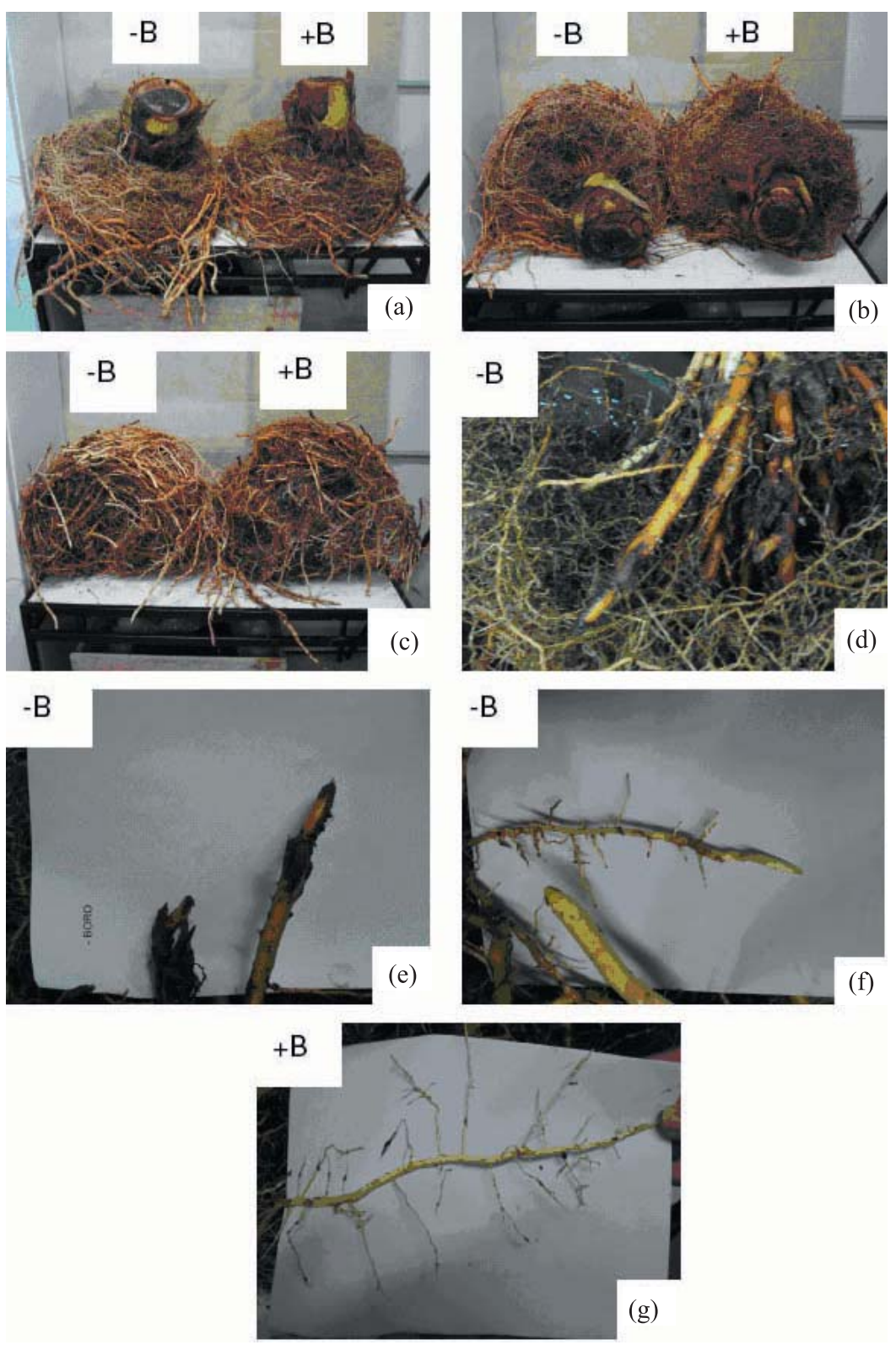

Figura 2. Sintomas visuais de deficiência de boro em raízes de coqueiro-anão verde. (a, b e c): imagens das raízes deficientes (-B) e normais (+B); (d) e (e): raízes com necroses e superbrotação; (f) e (g): raízes médias e finas nas plantas deficientes (-B) e normais $(+B)$, respectivamente.

fotoassimilados. Nesse caso, em deficiência de B, a alocação de C para o sistema radicular também será prejudicada. Todos esses fatores em conjunto, provavelmente, promoveram menor produção de matéria seca de raízes, principalmente finas (Quadro 3).

\section{Teores de nutrientes nas raízes}

Todas as seções de raízes das plantas deficientes apresentaram teores menores de B, com considerável perda na massa total de raízes secas. Nas plantas deficientes, a distribuição do teor de $\mathrm{B}$ entre as raízes de diferentes diâmetros sugere uma possível mobilidade deste nutriente entre raízes. Nas raízes grossas e médias o teor de $\mathrm{B}$ foi baixo, enquanto nas raízes finas observou-se o maior teor. A maioria das raízes finas pode ter sido formada após a indução da deficiência (61 dias após transplantio). Como nas plantas normais os maiores teores de B foram encontrados nas raízes grossas ou finas, constata-se que as plantas deficientes apresentaram um possível efeito adaptativo ao meio, havendo, possivelmente, translocação do $\mathrm{B}$ das raízes grossas para as finas. Outros fatos que contribuem com essa hipótese são: a pequena diferença entre os teores de $\mathrm{B}$ das seções de raízes das plantas deficientes 
e normais e o longo período entre a indução (61 dias após o transplantio) e a coleta final do experimento (464 dias após indução), além da menor diferença percentual entre o teor de $\mathrm{B}$ das raízes finas normais e deficientes (-23,6\%) quando comparado com as percentagens nas raízes médias normais e deficientes $(-26,7 \%)$, assim como nas raízes grossas $(-29,6 \%)$.

As raízes finas, por serem as principais responsáveis pela absorção de nutrientes pelo coqueiro (Passos, 1998), possivelmente, possuem maior atividade metabólica, o que exigiria mais B, entre outros nutrientes. Nas raízes grossas, mais lignificadas, parte do nutriente pode ter se acumulado nas paredes celulares, ligando-se com a pectina (Kobayashi et al.,1996; Ishii \& Matsunaga, 1996; Fleischer et al., 1998), e uma certa quantidade de B estaria livre para ser translocada. Dannel et al. (2000) encontraram resultados mostrando que o $\mathrm{B}$ ligado à parede celular de plantas de girassol não é totalmente imóvel, uma vez que aproximadamente 28 \% desse nutriente inicialmente presente na parede celular foi trocado ou liberado após três horas de omissão do B da solução nutritiva, ficando o restante aderido. Outro fato que corrobora a hipótese de translocação de B é a existência em raízes de um pool de reserva desse nutriente. Em girassol submetido a baixo fornecimento de $\mathrm{B}\left(0,01 \mathrm{mmol} \mathrm{L}^{-1}\right)$, do total desse nutriente nas raízes $\left(64,1 \mathrm{nmol} \mathrm{g} \mathrm{mf}^{-1}\right), 67,4,4$ e $27,9 \%$ estavam alocados na parede celular, no vacúolo e no citosol, respectivamente, ocorrendo troca de $\mathrm{B}$ entre esses compartimentos, porém 29 e 283 vezes mais lenta na parede celular do que no vacúolo e no citosol, respectivamente (Pfeffer et al., 2001).

Os teores de N, P, K, Cu e Zn foram maiores nas raízes das plantas deficientes em B (Quadro 4). Encontraram-se os maiores teores de $\mathrm{Mg}, \mathrm{S}$ e $\mathrm{Cu}$ nas raízes finas das plantas deficientes de B (Quadro 4). Possivelmente, a restrição do crescimento radicular imposto pela deficiência de B tenha favorecido o aumento dos teores dos nutrientes supramencionados (Quadro 3). Os teores de $\mathrm{Ca}, \mathrm{Mn}$ e $\mathrm{Zn}$ não diferiram entre tratamentos (Quadro 4).

As raízes, quando comparadas com as folhas, de maneira geral, apresentam menores teores de B (Apostol \& Zwiazek, 2004; Dechen \& Nachtigall, 2006). É possível que a demanda metabólica, nos processos que envolvem o B, nas raízes seja menor, quando comparada com a das folhas. De qualquer forma, tem sido demonstrado que a deficiência de $\mathrm{B}$ inibiu o crescimento radicular de uma série de culturas $(\mathrm{Hu}$ et al.,1997; Belvins \& Lukaszewski, 1998; Yeh et al., 2000; Viégas et al., 2004).

Os nutrientes $\mathrm{N}, \mathrm{P}, \mathrm{Ca}, \mathrm{Mg}, \mathrm{S}, \mathrm{Cu}, \mathrm{Fe}$ e $\mathrm{Zn}$ apresentaram maior teor nas raízes finas. Possivelmente, estas raízes são metabolicamente mais ativas, provocando assim maior demanda desses nutrientes.
Dos nutrientes avaliados, o K apresentou teor mais elevado nas raízes grossas, que são bastante lenhosas em comparação com as raízes médias e finas. Como o K não faz parte de compostos na planta (Malavolta et al., 1997), e existe apenas na forma iônica, é facilmente lixiviável do tecido. Como o processo de lavagem das raízes foi intenso, as raízes médias e finas, por apresentarem maior superfície específica, podem ter perdido K para a água em maior quantidade que as raízes grossas.

\section{Sintomas visuais nas raízes}

As plantas deficientes em B apresentaram os sintomas visuais dessa deficiência, nas raízes, similares aos descritos na literatura. Segundo Lima Filho \& Malavolta (1997), plantas de Stevia rebaudiana, com deficiência severa de $\mathrm{B}$, apresentando teor desse nutriente em torno de $20 \mathrm{mg} \mathrm{kg}^{-1}$ nas folhas, mostraram os primeiros sintomas nas raízes, com diminuição do crescimento, engrossamento, ramificação curta e escurecimento geral; as raízes estavam com as pontas necrosadas. Plantas de Curcubita pepo L. (abóbora), previamente cultivadas em solução completa, foram transferidas para solução sem B; após $6 \mathrm{~h}$, percebeu-se clara redução no alongamento radicular e, depois de $16 \mathrm{~h}$, o crescimento foi paralisado. A redução do crescimento radicular foi acompanhada dos sintomas visuais: elevação do diâmetro e do peso por unidade de comprimento dos ápices radiculares laterais; iniciação de primórdios radiculares laterais sempre no ápice radicular, com desenvolvimento de raízes laterais encurvadas; e escurecimento do tecido terminal da raiz (Lovatt et al., 1981).

\section{CONCLUSÕES}

1. A deficiência de B promoveu menor teor desse nutriente nas raízes de todos os diâmetros; os menores teores de $\mathrm{B}$ ocorreram nas raízes médias.

2. Encontraram-se os maiores teores de N, P, Ca, $\mathrm{Mg}, \mathrm{S}, \mathrm{B}, \mathrm{Cu}, \mathrm{Fe}, \mathrm{Mn}$ e $\mathrm{Zn}$ nas raízes finas do coqueiro em ambos os tratamentos; já os teores de $\mathrm{K}$ foram maiores nas raízes grossas.

3. A deficiência de $\mathrm{B}$ aumentou os teores de $\mathrm{N}, \mathrm{Pe}$ $\mathrm{K}$ em todas as raízes e os teores de $\mathrm{Mg}, \mathrm{S}$, $\mathrm{Cu}$ e $\mathrm{Zn}$ nas raízes finas, porém não alterou os teores de $\mathrm{Ca}, \mathrm{Fe}$ e Mn.

4. Nas plantas deficientes de $B$, a produção de raízes totais e finas foi reduzida em 29,7 e 48,3\%, respectivamente.

\section{LITERATURA CITADA}

APOSTOL, K.G. \& ZWIAZEK, J.J. Boron and water uptake in jack pine (Pinus banksiana) seedlings. Environ. Exper. Bot., 51:145-153, 2004. 
BLEVINS, D.G. \& LUKASZEWSKI, K.M. Boron in plant structure and function. Ann. Rev. Plant Physiol. Plant Molec. Biol., 49:481-500, 1998.

BRASIL, F.C. Estudos de características radiculares de pastagens de Brachiaria humidicola com auxílio de análise de imagens. Seropédica, Universidade Federal Rural do Rio de Janeiro, 2001. 137p. (Tese de Mestrado)

BROSCHAT, T.K. Boron deficiency in palms. University of Florida, Ifas Extension, 2005. Disponível em: <http:// edis.ifas.ufl.edu.> Acesso em 20 de nov. de 2007.

CAKMAK, I.; KURZ, H. \& MARSCHNER, H. Short-term effects of boron, germanium and high light intensity on membrane permeability in boron deficient leaves of sunflower. Physiol. Plant., 95:11-18, 1995.

CINTRA, F.L.D.; FONTES, H.R. \& LEAL, M.L.S. Distribuição do sistema radicular do coqueiro gigante do Brasil submetido a diferentes sistemas de manejo do solo. $R$. Bras. Ci. Solo, 20:327-332, 1996

DANNEL, F.; PFEFFER, H. \& RÖMHELD, V. Characterization of root boron pools, boron uptake and boron translocation in sunflower using the stable isotopes ${ }^{10} \mathrm{~B}$ and ${ }^{11} \mathrm{~B}$. Aust. J. Plant Physiol., 27:397-405, 2000.

DECHEN, R.A. \& NACHTIGALL, G.R. Micronutrientes. In: FERNANDES, M.S. Nutrição mineral de plantas. Viçosa, MG, Sociedade Brasileira de Ciência do Solo, 2006. p.327. 354 .

FABIÃO, A.M.D.; MADEIRA, M. \& STEEN, E. Root mass in plantations of Eucalyptus globulus in Portugal in relation to soil characteristics. Arid Soil Res. Rehabilit., 1:185-194, 1987.

FITTER, A.H. Characteristics and functions of root systems. In: WAISEL, Y.; ESHEL, A. \& KAFKAFI, U. Plant root: The Hidden Half. New York, Dekker, 1991. p.3-22

FLEISCHER, A.; TITEL, C. \& EHWALD, R. The boron requirement and cell wall properties of growing and stationary suspension-cultured Chenopodium album L. cells. Plant Physiol., 117:1401-1410, 1998.

FREITAS, M.S.M. Flavonóides e nutrientes minerais em folhas de maracujazeiro amarelo e deficiência de macronutrientes e boro em maracujazeiro doce. Campos dos Goytacazes, Universidade Estadual do Norte Fluminense Darcy Ribeiro, 2006. 106p. (Tese de Doutorado)

FRÉMOND, Y.; ZILLER, R. \& LAMOTHE, M.N. El Cocotero. Barcelona, Blume, Coleccion Agricultura Tropical, 1975. $236 p$.

HU, H.; PENN, S.G.; LEBRILLA, C.B. \& BROWN, P.H. Isolation and characterization of soluble boron complexes in higher plants. The mechanism of phloem mobility of boron. Plant Physiol., 113:649-655, 1997.

HU, H. \& BROWN, P.H. Localization of boron in the cell walls of squash and tobacco and its association with pectin. Plant Physiol., 105:681-689, 1994.

ISHII, T. \& MATSUNAGA, T. Isolation and characterization of a boron rhamnogalacturonan II complex from cell walls of sugar beet pulp. Carbohydr. Res., 284:1-9, 1996.
JACKSON, M.L. Soil chemical analysis. 5.ed. Englewood Cliffs, Prentice Hall, 1965. 498p.

KOBAYASHI, M.; MATOH T. \& AZUMA J. Two chains of rhamnogalacturonan II are cross-linked by borate-diol ester bonds in higher plant cell walls. Plant Physiol., 110: 1017-1020, 1996.

LIBARDI, P.L. Dinâmica da água no solo. São Paulo, EDUSP, 1995. 497p.

LIMA FILHO, O.F. \& MALAVOLTA, E. Sintomas de desordens nutricionais em estévia [Stevia rebaudiana (Bert.) Bertoni]. Sci. Agric., 54:53-61, 1997.

LOVATT, C.J.; ALBERT, L.S. \& TREMBLAY, G.C. Synthesis salvage, and catabolism of uridine nucieotides in borondeficient squash roots. Plant Physiol., 68:1389-1394, 1981.

MACÊDO, J.L.V.; GASPAROTO, L. \& CUNHA, R.N.V. Deficiência de boro em coqueiro - Sintomas e correção. Manaus, Embrapa Amazônia Ocidental, 1999. (Instruções Técnicas, 4)

MALAVOLTA, E.; VITTI, G.C. \& OLIVEIRA, S.A. Avaliação do estado nutricional das plantas: Princípios e aplicações. 2.ed. Piracicaba, POTAFOS, 1997. 319p.

MATOH, T.; ISHIGAKI, K.; OHNO, K. \& AZUMA, J. Isolation and characterization of a boron-polysaccharide complex from radish roots. Plant Cell Physiol., 34:639-642, 1993.

MIRISOLA FILHO, L.A. Avaliação do estado nutricional do coqueiro-anão (Cocos nucifera L.) na região Norte Fluminense. Campos dos Goytacazes, Universidade Estadual do Norte Fluminense Darcy Ribeiro, 1997. 57p. (Tese de Mestrado)

MONNERAT, P.H. Notas das aulas da disciplina: Nutrição mineral de plantas-LFIT-CCTA-UENF. Não Publicado

MOREIRA, F.M.S. \& SIQUEIRA, J.O. Microbiologia e bioquímica do solo. Lavras, Universidade Federal de Lavras, 2002. 652p.

PASSOS, E.E.M. Morfologia do coqueiro. In: FERREIRA J.M.S.; WARWICK. D.R.N. \& SIQUEIRA, L.A., orgs. A cultura do coqueiro no Brasil. 2.ed. Brasília, EmbrapaSPI, 1998. p.57-64.

PFEFFER, H.; DANNEL, F. \& RÖMHELD, V. Boron compartmentation in roots of sunflower plants of different boron status: A study using the stable isotopes $\mathrm{B}^{10}$ and $\mathrm{B}^{11}$ adopting two independent approaches. Physiol. Plant., 113:346-351, 2001

PINHO, L.G.R. Controle da mancha anelar dos frutos de coqueiro-anão verde no noroeste do Estado do Rio de Janeiro: Efeitos da aplicação de ácido bórico. Campos dos Goytacazes, Universidade Estadual do Norte Fluminense Darcy Ribeiro, 2004. 44p. (Tese de Mestrado)

RUSSEL, R.S. Plant root systems - Their function and interaction with the soil. In: SYMPOSIUM ON THE SOIL / ROOT SYSTEM, 1981, Londrina. Proceedings. Londrina, Instituto Agronômico do Paraná, 1981. p.3-20

SANTOS, A.L.; MONNERAT, P.H. \& ALVES, E.A.B. Teor foliar de boro em função da aplicação de bórax na axila foliar de coqueiro-anão verde no Norte Fluminense. Pesq. Agropec. Desenvol. Sustentável, 1:165-171, 2003. 
SOBRAL, F.L. Nutrição e adubação do coqueiro. In: FERREIRA, J.M.S.; WARWICK, D.R.N. \& SIQUEIRA, L.A., eds. A cultura do coqueiro no Brasil. Aracaju, Embrapa-SPI, 1998. p.129-157.

VIÉGAS, I.J.M.; THOMAZ, M.A.A.; SILVA, J.F.; CONCEIÇÃO, H.E.O. \& NAIFF, A.P.M. Efeito da omissão de macronutrientes e boro no crescimento, nos sintomas de deficiências nutricionais e na composição mineral de plantas de camucamuzeiro. R. Bras. Frutic., 26:315-319, 2004.
WITSCHORECK, R.; SCHUMACHER, M.V. \& CALDEIRA, M.V.W. Estimativa da biomassa e do comprimento de raízes finas em Eucalyptus urophylla S.T. Blake no município de Santa Maria-RS. R. Árvore, 27:177-183, 2003.

YEH, D.M.; LIN, L. \& WRIGHT, C.J. Effects of mineral nutrient deficiencies on leaf development, visual symptoms and shoot-root ratio of Spathiphyllum. Sci. Hortic., 86:223233,2000 